\title{
Pathophysiological and Clinical Significance of Coronary Artery Ectasia - A Review
}

\author{
SYED DAWOOD MD.TAIMUR ${ }^{1}$, SAIDUR RAHMAN KHAN ${ }^{1}$, MD.HASANUR RAHMAN ${ }^{1}$, HEMANTO I. GOMES $^{1}$, \\ FARZANA ISLAM ${ }^{2}$, MD. ABU SIDDIQUE ${ }^{3}$,KH. QUMRUZZAMAN ${ }^{3}$. UMME KULSUM ${ }^{4}$ MD. ASHRAF UDDIN SULTAN $^{3}$ \\ ${ }^{1}$ Department of Cardiology, Ibrahim Cardiac Hospital \& Research Institute, ${ }^{2}$ Dept.of Paediatric Nephrology, Bangabandhu Sheikh \\ Mujib Medical University (BSMMU), ${ }^{3}$ Dept. of Cardiology, Bangabandhu Sheikh Mujib Medical University (BSMMU), ${ }^{4}$ Dept. \\ of Gynae \& Obs, Bangabandhu Sheikh Mujib Medical University (BSMMU)
}

Address for Correspondence: Dr.Syed Dawood Md.Taimur, Department of Cardiology, Ibrahim Cardiac Hospital \& Research Institute, Email: sdmtaimur@yahoo.com

\begin{abstract}
Coronary artery ectasia is a relatively common entity characterized by inappropriate dilatation of the coronary vasculature. The exact mechanism of its development is unknown, but evidence suggests a combination of genetic predisposition, common risk factors for coronary artery disease and abnormal vessel wall metabolism. It frequently coexists with aneurysms elsewhere, mostly involving the aorta. In this review, the flow disturbances that are associated with this condition and the imaging modalities, which can be used for diagnosis and prospective follow-up are described. The prognosis of coronary ectasias is controversial and prospective studies focusing on conservative or invasive strategies to prevent cardiac complications are needed.
\end{abstract}

Keywords: Coronary artery ectasia (CAE); Coronary flow; Atherosclerosis

\section{Introduction}

Coronary artery ectasia (CAE) has been observed by pathologists and cardiologists for more than two centuries. This coronary anomaly was first described by Morgagni in 1761. Bourgon was the first to describe the postmortem finding of right coronary artery (RCA) dilatation in a patient who experienced sudden death in $1812 .^{1}$ The term ectasia was first used by Bjork in 1966 to describe dilated coronary arteries. $^{2}$ The literature prior to this date consisted of only postmortem reports. Coronary angiography and new diagnostic tools have enabled clinicians to discover more cases of ectasia. However, not all patients with ectasia are symptomatic and receive coronary angiography examination; hence, the real incidence is unknown. The reported incidence is between $0.3 \%$ and $4.9 \%$ at autopsy and during coronary angiography. ${ }^{3-5}$ Zeina et al. determined that the prevalence of CAE in consecutive participants who underwent coronary multidetector computed tomography (MDCT) was 8\%. ${ }^{6}$ Sharma et al. found an incidence as high as $12 \%$ in an Indian population, ${ }^{7}$ which may have different demographic characteristics. There is a male preponderance, with a maleto female ratio of 3: $1 .^{4,8,9}$ The proximal and middle parts of the RCA are most commonly affected by ectasia, although the reasons for this are not clear. Involvement of the left anterior descending artery and left circumflex artery is variable. The left main coronary artery is less commonly involved. Most cases of CAE involve only a single vessel. Disturbance in blood filling and washout are major characteristics of CAE. Delayed antegrade filling, a segmental back flow phenomenon, and local deposition of dye (stasis) in the dilated coronary segment have been observed during imaging. ${ }^{10,11}$

\section{Definition and classification}

There are various methods for defining CAE. Hartnell et al. defined CAE as an arterial segment with a diameter at least 1.5 times the diameter of the adjacent normal coronary artery $^{5}$. The most commonly used angiographic definition of CAE, albeit arbitrary, is the diameter of the ectatic segment being more than 1.5 times larger compared with an adjacent healthy reference segment. ${ }^{4,48}$ However, as the distribution of CAE is quite variable and not always focal, normal reference segments may not be readily apparent, and this definition potentially underestimates the true incidence of the disease. More detailed definition characteristics, for example employing larger diameter ratio or incorporating angiographic flow alterations, may enhance detection accuracy during angiography but also may further underestimate the true incidence of the disease. Markis et al provided the following classification of CAE based on the extent of coronary involvement: type I, diffuse ectasia of two or three vessels; type II, diffuse disease in one vessel and localized disease in another vessel; type III, diffuse ectasia of one vessel only; and type IV, localized or segmental ectasia. ${ }^{8}$ This classification is used extensively. Plehn et al preferred to use the term coronary artery aneurysm for segmental ectasia, reserving 
the term ectasia for diffuse vessel involvement. ${ }^{12}$ They classified aneurysms as small ( $<5 \mathrm{~mm})$, medium $(5-8 \mathrm{~mm})$, or giant (e” $8 \mathrm{~mm}$ ). In addition, coronary artery aneurysm has been classified as the fusiform or saccular type based on the anatomic shape of the ecstatic segment. There is no general concept concerning the critical diameter required for the development of rupture. To date, only a few reports have described the anatomic changes that occur in CAE over time. Plehn et al. reported a patient who presented with ectatic lesions that rapidly progressed to aneurysmatic lesions within 3 years. ${ }^{12}$ The patient was treated with aneurysm ligation and coronary artery bypass grafting (CABG). A coronary aneurysm was diagnosed if the internal lumen diameter was $>4.0 \mathrm{~mm}$. A coronary artery ectasia was defined as a distension of a part of a coronary vessel of up to one and a half times the diameter of an adjacent normal segment. Periodic careful follow-up of patients with CAE is recommended.

\section{Etiology and pathogenesis}

More than $50 \%$ of CAE cases are reportedly caused by atherosclerosis. ${ }^{4,9,11}$ Compensatory vessel enlargement in the presence of coronary atherosclerotic plaques is a common phenomenon that is viewed as positive remodeling. ${ }^{13}$ Progressive overcompensation leading to ectasia may be caused by an inadequate extent of media atrophy and fracture of the internal elastic lamina, as well as atypical rearrangement of smooth muscle cells. ${ }^{14,15}$ Virmani et al. provided a detailed pathologic characterization of CAE, including lipid deposition with foam cells, fibrous caps and significant loss of musculoelastic vascular wall components as the main histological abnormalities. ${ }^{16}$

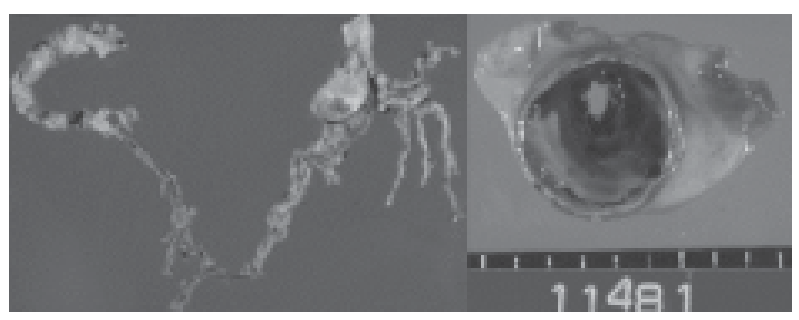

Fig.-1: Pathogenesis of Coronary Artery Ectasia

The reason why stenosis develops in some individuals with atherosclerosis while dilatation occurs in others is unknown. Genetic susceptibility is likely to explain why certain individuals are at risk of developing CAE. ${ }^{17,18}$ Many other clinical entities can cause dilation of the coronary arteries, such as syphilis, mycotic or bacterial infection, Kawasaki disease, trauma, congenital heart disease, inflammatory disorders, connective tissue disorders such as Marfan syndrome, scleroderma, systemic lupus, Ehlers-Danlos syndrome, periarteritis nodosa, Behcet's disease and congenital defects. ${ }^{11,19-21}$ Prolonged exposure to herbicides such as 2, 4, 5-T (trichlorophenoxyacetic acid) and 2,4-D (dichlorophenoxyacetic acid) has been associated with CAE. ${ }^{22}$ These herbicides, which contain acetyl cholinesterase inhibitors, can increase the levels of acetylcholine and stimulate the production of nitric oxide. Nitric oxide can stimulate relaxation of the coronary artery. At present, it is not known whether or not chronic relaxation of the smooth muscle layer of the coronary artery causes CAE ${ }^{23} \mathrm{CAE}$ can also be iatrogenic in origin, for example after percutaneous coronary intervention (PCI). Chiu et al reported a patient who developed coronary artery aneurysm after successful stent implantation for a chronic totally occluded lesion. ${ }^{24}$ Interestingly, the aneurysm spontaneously regressed a few months later without further intervention. It was thought that the most likely mechanism for this was shear stress inducing vessel positive remodeling after an intervention procedure, with subsequent negative remodeling when the shear stress returned to baseline.

Lamblin et al found that patients with CAE had a higher percentage of the $5 \mathrm{~A} / 5 \mathrm{~A}$ polymorphism of metalloproteinase-3 (MMP-3), which is actively involved in the proteolysis of extracellular matrix proteins. ${ }^{24}$ The levels of inflammatory markers such as plasma interleukin6, C-reactive protein, V-CAM, I-CAM and E-selectin are elevated in CAE patients. ${ }^{26-29}$ This suggests a role for the inflammatory process in this setting. Pinar et al. determined that CAE was associated with the classical cardiovascular risk factors except for diabetes, which was rare in patients with isolated CAE. ${ }^{30}$ This negative correlation between diabetes and CAE has also been reported by others. Williams et al found impaired nitric oxide-mediated vasodilatation in patients with non-insulin-dependent diabetes. ${ }^{31}$ However, Zeina et al demonstrated that there was no apparent correlation between CAE and hypertension, hyperlipidemia, diabetes, smoking and a family history of coronary artery disease. ${ }^{6}$ The actual relationship between CAE and traditional cardiovascular risk factors still needs to be clarified by further study. Considering all of the above findings, Manginas and Cokkinos speculated that CAE occurs due to two different mechanisms in two distinct patient groups: (1) commonly in patients with concomitant coronary artery disease due to severe and chronic arterial inflammation; and (2) rarely in subjects without coronary atherosclerosis as a result of exogenous interstitial nitric oxide vascular overestimation. ${ }^{11}$ 
Immunoreactivity against matrix metalloproteinase (MMP)-1, and MMP-2 was observed in smooth muscle cells, macrophages, lymphocytes, and endothelial cells of the vasa vasorum or neovasculature. MMP-9 immunoreactivity was also localized in intimal foamy macrophages and round cells (macrophages and lymphocytes) of the media and adventitia. MMP-1 increased with the lumen diameter of the ectatic arteries. The ratio of immunoreactivity against both MMP-2 and MMP-9 to that against tissue inhibitor of metalloproteinase (TIMP)-2 also increased with the lumen diameter, but it no longer increased when the diameter was over $10 \mathrm{~mm}$. These observations suggest that the MMP-TIMP system appears to play a significant role in the development of coronary ectasia

Clinical Sequelae and Prognosis: In the majority of cases ( $\sim 85 \%)$, CAE accompanies atherosclerotic coronary disease. ${ }^{4,8,48-49}$ The clinical presentation and the longterm cardiac complications are mostly associated with the severity of the coexisting coronary lesions. In this population, it has been repeatedly shown that CAE does not confer an additional risk to that which is attributed to coexisting coronary stenosis $4,8,48$. In the largest series from the CASS study, the presence of CAE did not affect the adjusted 5-year survival of patients with coronary artery disease (75 vs. 81\%). ${ }^{4}$

In a recent report from our group corresponding to more modern medical management, the 2-year survival in the two groups, with and without CAE, was also similar (96.7 vs. 94.8\%). ${ }^{48}$ Very recently, Baman et al. ${ }^{46}$ using more stringent criteria for identifying patients with CAE, reported a significant adverse outcome among 276 patients they studied, with a 5-year mortality of $29.1 \%$. Although autopsy reports frequently document thrombus within a CAE, the true incidence of thrombotic occlusion is unknown, requiring a large prospective angiographic study. Non-invasive methods, especially MRI, may offer a means of prospectively following these patients.

The clinical course of the patients with isolated CAE (with no or non-significant coronary stenoses) deserves special attention. Despite the absence of flow limiting coronary lesions in this small group of patients, Krueger et al. ${ }^{10}$ convincingly documented the presence of angina, positive exercise stress test and pacing-induced myocardial ischemia in patients with 'dilated coronaropathy'. In addition, unstable coronary syndromes may occur despite absence of stenoses: In our study, 38.7\% of patients with isolated CAE were reported as having a history of myocardial infarction in the corresponding myocardial territory. ${ }^{48}$ Overall, however, cardiac event rate in this patient group appears to be low and clinical follow-up suggests a relatively favorable prognosis. As reported previously ${ }^{4}$ mortality approximates $2 \%$ per year.

\section{Diagnostic methods}

Coronary angiography is now the criterion standard for diagnosing CAE. Coronary angiography offers a detailed definition of coronary anatomy, making it possible to characterize the distribution and size of coronary aneurysms and also to detect coronary stenosis. A treadmill exercise test and thallium-201 myocardial perfusion scan can be used to evaluate myocardial ischemia caused by CAE. Intravascular ultrasound can be used to assess the luminal size and condition of the arterial walls, and also to differentiate true from false aneurysms caused by plaque rupture. ${ }^{40}$ Magnetic resonance imaging has been successfully used to assess coronary anatomy
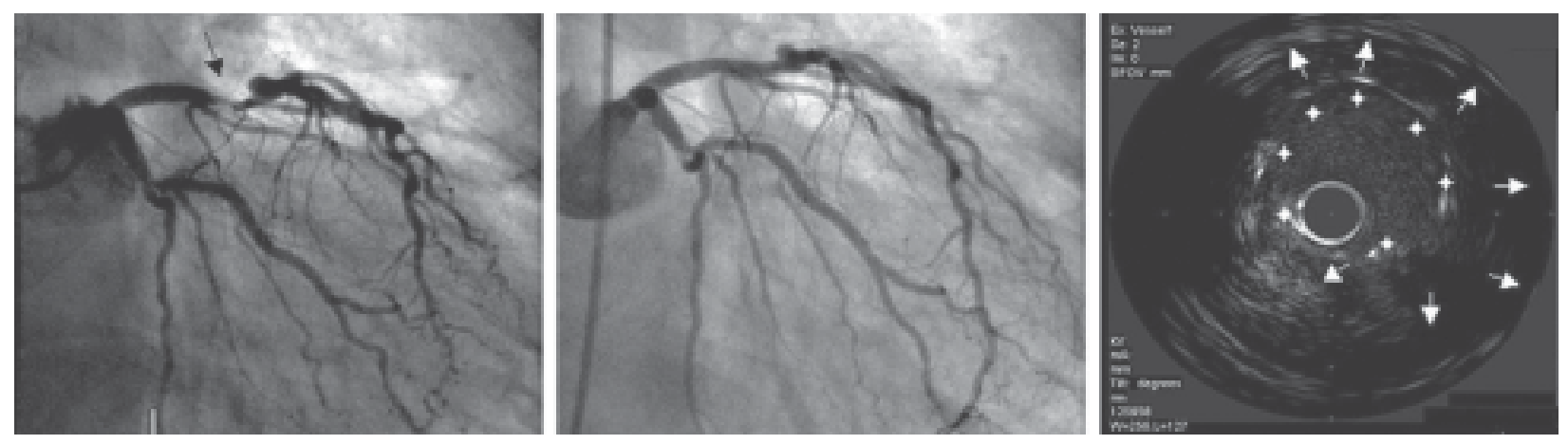

Fig.-2 : Coronary angiogram of the left anterior descending artery (right anterior oblique projection) showing a severe mid-segment stenosis (black arrow) adjacent to a coronary ectatic segment, before stent placement (left), after stent placement (middle), and intracoronary ultrasound image (right) within the proximal ectatic segment exhibiting inadequate apposition of stent struts (asterisks) against the vessel wall (white arrows) despite stent overexpansion. 
in patients with CAE. Greil et al reported a small series of adolescents and young adults with Kawasaki disease, who were diagnosed by coronary magnetic resonance angiography. ${ }^{41}$ MDCT is one of the newest tools used to diagnose $\mathrm{CAE}$, and it is not invasive like coronary angiography. Zeina et al found a high prevalence (8\%) of CAE when using MDCT as a diagnostic tool. ${ }^{6}$ The first congenital CAE diagnosed by MDCT was reported by Ayusawa et al in 2008. ${ }^{42}$

\section{Treatment}

CAE is not a benign coronary anomaly. Sorrel et al suggested treating CAE patients with: (1) anticoagulation therapy, utilizing chronic warfarin therapy to offset the risk of thrombus formation and to keep the international normalized ratio at around 2.0-2.5; (2) antiplatelet therapy, utilizing aspirin (80-360 mg/day) to minimize platelet aggregation; and (3) antispasm therapy, utilizing calciumchannel blockers. ${ }^{23}$ Nitrates could also be used, but added care should be emphasized to provide a nitrate-free "holiday" and prevent chronic exposure to these agents. Therapy should be tailored to each individual patient because of the serious bleeding complications associated with warfarin use. Tuncer et al reported two cases of CAE, one in a patient with myocardial infarction and one with unstable angina. ${ }^{43} \mathrm{~A}$ large thrombus was seen in both patients and they were treated with aspirin, warfarin and metoprolol. One patient received MDCT after follow-up, which revealed that the thrombus had almost completely dissolved after 3 months. Warfarin was then discontinued in both cases and clopidogrel was given. But these treatment strategies have not been studied prospectively. Heparin and thrombolytic therapy have been successfully used for recanalization. For patients with coexisting obstructive lesions and refractory angina despite medical treatment, PCI can be performed. But there can be difficulties during stent deployment because the ectatic arteries are usually much larger than normal arteries. Selection of a stent of adequate size and its expansion are very important, and can be determined by intravascular ultrasound. Rha et al reported a challenging case of implantation of two 3.5 18 sirolimus eluting stents parallel to each other in a large ecstatic coronary artery. ${ }^{44}$ They suggested that in lesions, which have a large reference diameter, the clinician could consider parallel stenting using drug-eluting stents as a new intervention strategy. CABG has been used for many years for the treatment of significant coronary artery disease coexisting with CAE, and the postoperative outcome is uniformly good. In our opinion, treatment should be tailored according to clinical manifestations and the number and involvement of the coronary arteries. Medical therapy is recommended for patients with symptomatic nonobstructive CAE. Surgery (CABG, aneurysm ligation, or aneurysmorrhectomy) is a better choice for patients who are refractory to coronary medical therapy and not suited for PCI.

\section{Prognosis:}

There are different opinions about the prognosis of CAE. ${ }^{8,45-47}$ Markis et al reported an annual mortality rate of $15 \%$ during a mean follow-up period of 24 months. ${ }^{8}$ Baman et al reported a significant adverse outcome among the 276 CAE patients they studied, with a 5-year mortality rate of $29.1 \% .{ }^{46}$ Recently, because the techniques and equipment for revascularization have significantly improved, the prognosis of CAE seems to be better. Valente et al reported that the prognosis of CAE was good with a low mortality rate (2\%), ${ }^{47}$ possibly because their patients with ST-elevated myocardial infarction and acute coronary syndrome all underwent PCI and the most severe cases with coexisting coronary stenosis underwent CABG.

\section{Conclusion}

Coronary artery ectasia represents a not uncommon form of atherosclerotic coronary artery disease, seen in 5\% of patients undergoing coronary angiography. Many unanswered questions remain regarding their exact etiology, prognosis and therapy. The introduction of genetic studies, new non-invasive modalities, especially MRI, and the systematic testing of modern antiplatelet and vasoactive medications, may offer significant means of improving their prognosis.

\section{References}

1. Packard M, Weehsler HF. Aneurysm of the coronary arteries.Arch Intern Med 1929; 43: 1-14.

2. Bjork L. Ectasia of the coronary arteries. Radiology1966; 87: 33-34.

3. Oliveros RA, Falsetti HL, Carroll RJ, Heinle RA, Ryan GF.Atherosclerotic coronary artery aneurysm: report of five cases and review of literature. Arch Intern Med 1974; 134: 1072-76.

4. Swaye PS, Fisher LD, Litwin P, et al. Aneurysmal coronary artery disease. Circulation 1983; 67: 134-38.

5. Hartnell GG, Parnell BM, Pridie RB. Coronary artery ectasia. Its prevalence and clinical significance in 4993 patients. $\mathrm{Br}$ Heart J 1985; 54: 392-95.

6. Zeina AR, Sharif D, Blinder J, Rosenschein U, Barmeir E. Noninvasive assessment of coronary artery ectasia using multidetector computed tomography. Coron Artery Dis 2007; 18: $175-80$. 
7. Sharma SN, Kaul U, Sharma S, et al. Coronary arteriographic profile in young and old Indian patients with ischemic heart disease: a comparative study. Indian Heart J 1990; 42: 365369.

8. Markis JE, Joffe CD, Cohn PF, Feen DJ, Herman MV, Gorlin R. Clinical significance of coronary arterial ectasia. Am J Cardiol 1976; 37: 217-22.

9. Befeler B, Aranda MJ, Embi A, Mullin FL, El-Sherif N, Lazzara R. Coronary artery aneurysm: study of their etiology, clinical course and effect on left ventricular function and prognosis. Am J Med 1977; 62: 597-607.

10. Kruger D, Stierle U, Herrmann G, Simon R, Sheikhzadeh A.Exercise-induced myocardial ischemia in isolated coronary artery ectasias and aneurysms(“dilated coronopathy”). J Am Coll Cardiol 1999; 34: 1461-70.

11. Manginas A, Cokkinos DV. Coronary artery ectasias: imaging, functional assessment and clinical implications. Eur Heart $J$ 2006; 27: 1026-31.

12. Plehn G, van Bracht M, Zuehlke C, et al. From atherosclerotic coronary ectasia to aneurysm: a case report and literature review. Int J Cardiovasc Imaging 2006; 22: 311-16.

13. Varnava A. Coronary artery remodeling. Heart 1998; 79: 109-10.

14. Crawford T, Levene CI. Medial thinning in atheroma. $J$ Pathol Bacteriol 1953; 66: 19-23.

15. Bendeck MP, Zempo N, Clowes AW, Galardy RE, Reidy MA. Smooth muscle cell migration and matrix metalloproteinase expression after arterial injury in the rat. Circ Res 1994; 75: 539-45.

16. Virmani R, Robinowitz M, Atkinson JB, Forman MB, Silver MD, McAllister HA. Acquired coronary arterial aneurysm: an autopsy study of 52 patients. Hum Pathol 1986; 17: 575-83.

17. Kajinami K, Kasashima S, Oda Y, Koizumi J, Katsuda S, Mabuchi H. Coronary ectasia in familial hypercholesterolemia: histopathological study regarding matrix metalloproteinases. Mod Pathol 1999; 12: 1174-80.

18. Akdemir R, Qzhan H, Gunduz H, et al. HLA-DR B1 and DQ B1 polymorphisms in patients with coronary artery ectasia. Acta Cardiol 2004; 59: 499-502.

19. Lam CS, Ho KT. Coronary artery ectasia: a ten-year experience in a tertiary hospital in Singapore. Ann Acad Med Singapore 2004; 33: 419-22.

20. Tomaru A, Takigawa K, Kagawa N, et al. Coronary artery ectasia—a case report and literature review. Angiology 1993; 44: 415-19.

21. Tatli E, Surucu H, Aktoz M, Buyuklu M. Coronary artery ectasia in a patient with Behcet's disease. Saudi Med J 2007; 28: 1281-82.

22. England JF. Herbicides and coronary ectasia. Med J Aust 1981; 1: 371.

23. Sorrel VL, Davis MJ, Bove AA. Current knowledge and significance of coronary artery ectasia: a chronologic review of the literature, recommendations for treatment, possible etiologies, and future considerations. Clin Cardiol 1998; 21: 157-60.

24. Chiu FC, Liu SC, Lin JW, Hwang JJ, Tseng CD. Development of a coronary artery aneurysm following stent implantation in a chronic, totally occluded lesion. Acta Cardiol Sin 2007; 23: 203-207.

25. Lamblin N, Bauters C, Hermant X, Lablanche JM, Helbecque $\mathrm{N}$, Amouyel P. Polymorphisms in the promoter regions of MMP-2, MMP-3, MMP-9 and MMP-12 genes as determinants of aneurysmal coronary artery disease. $J \mathrm{Am}$ Coll Cardiol 2002; 40: 43-48.

26. Adiloglu AK, Can R, Nazli C, et al. Ectasia and severe atherosclerosis: relationships with Chlamydia pneumoniae, Helicobacter pylori, and inflammatory markers. Tex HeartInst J 2005; 32: 21-27.

27. Turban H, Erbay AR, Yasar AS, Balci M, Bicer A, Yetkin E. Comparison of C-reactive protein levels in patients with coronary artery ectasia versus patients with obstructive coronary artery disease. Am J Cardiol 2004; 94: 1303-06.

28. Tokgozoglu L, Ergene O, Kinay O, Nazli C, Hascelik G,Hoscan Y. Plasma interleukin-6 levels are increased in coronary artery ectasia. Acta Cardiol 2004; 59: 515-19.

29. Turhan H, Erbay AR, Yasar AS, et al. Plasma soluble adhesion molecules; intercellular adhesion molecule-1, vascular cell adhesion molecule- 1 and E-selectin levels in patients with isolated coronary artery ectasia. Coron Artery Dis 2005; 16: 45-50.

30. Pinar BE, Lopez Palop R, Lozano Martinez-Luengas I, et al.Coronary ectasia: prevalence, and clinical and angiographic characteristics. Rev Esp Cardiol 2003; 56: 473-79.

31. Williams SB, Cusco JA, Roddy MA, Johnstone MT, Creager MA. Impaired nitric oxide-mediated vasodilatation in patients with non-insulin-dependent diabetes mellitus. J Am Col lCardiol 1996; 27: 567-74.

32. Sayin T, Doven O, Berkalp B, Akyurek O, Gulec S, Oral D. Exercise-induced myocardial ischemia in patients with coronary ectasia without obstructive coronary artery disease. Int J Cardiol 2001; 78: 143-49.

33. Bove AA, Vlietstra RE. Spasm in ectatic coronary arteries. Mayo Clin Proc 1985; 60: 822-6.

34. Suzuki H, Takeyama Y, Hamazaki Y, et al. Coronary spasm in patients with coronary ectasia. Cathet Cardiovasc Diagn 1994; 32: $1-7$.

35. Perlman PE, Ridgeway NA. Thrombus and anticoagulation therapy in coronary ectasia. Clin Cardiol 1989; 12: 541-42.

36. Huikuri HV, Mallon SM, Myerburg RJ. Cardiac arrest due to spontaneous coronary artery dissection in a patient with coronary ectasia-a case report. Angiology 1991; 42: 148-51.

37. Gore I, Smith J, Clancy R. Congenital aneurysms of the coronary arteries with report of a case. Circulation 1959; 19: 221-27.

38. Tuzun N, Tanriverdi H, Evrengul H, Kuru DS, Ergene AO. Aortic elastic properties in patients with coronary artery ectasia. Circ J 2007; 71: 506-10. 
39. Stajduhar KC, Laird JR, Rogan KM, Wortham DC. Coronary arterial ectasia: increased prevalence in patients with abdominal aortic aneurysm as compared to occlusive atherosclerotic peripheral vascular disease. Am Heart J1993; 125: 86-92.

40. Garrand TJ, Mintz GS, Popma JJ, Lewis SA, Vaughn NA, Leon MB. Intravascular ultrasound diagnosis of a coronary artery pseudoaneurysm following percutaneous transluminal coronary angioplasty. Am Heart J 1993; 125: 880-82.

41. Greil GF, Stuber M, Botnar RM, et al. Coronary magnetic resonance angiography in adolescents and young adults with Kawasaki disease. Circulation 2002; 105: 908-11.

42. Ayusawa M, Sato Y, Kanamaru H, et al. Multidetector-row computed tomographic depiction of congenital coronary artery aneurysms and ectasia. Int J Cardiol 2008; 127: e172-74.

43. Tuncer C, Sokmen G, Sokmen A, Suner A. Diffuse coronary ectasia and intracoronary thrombus involving left circumflex coronary artery and presenting as acute coronary syndrome: report of two cases. Int J Cardiol 2008; 128: e25-27.
44. Rha SW, Wani SP, Oh DJ. Parallel stenting using two sirolimuseluting stents in an ectatic coronary artery stenosis. Heart 2007; 93: 976.

45. Ramappa P, Kottam A, Kuivanemi H, Thatai D. Coronary artery ectasia-is it time for a reappraisal? Clin Cardiol 2007; 30: $214-17$.

46. Baman TS, Cole JH, Devireddy CM, Sperling LS. Risk factors and outcomes in patients with coronary artery aneurysms.Am J Cardiol 2004; 93: 1549-51.

47. Valente S, Lazzeri C, Giglioli C, et al. Clinical expression of coronary artery ectasia. J Cardiovasc Med 2007; 8: 815-20.

48. Demopoulos V, Olympois C, Fakiolas C, Pissimissis E, Economides N, Adamopoulou E, Foussas S,Cokkinos DV, The natural history of anuerysmal coronary artery disease.Heart 1997; 78: 136-41.

49. Farto-e-Abreu, Mesquita A, Silva JA, Seabra Comez R. Coronary artery ectesia: clinical and angiographic characteristics and prognosis.Rev Port Cardiol 1993; 12: 30510 . 